\title{
Analysis of the Course of Birth and the Early Postpartal Period in Pigs After Hormonal Partus Induction with Special Consideration of Complication Rate
}

\author{
Wolfgang Zaremba ${ }^{1}$, , Thomas Udluft ${ }^{1}$, Klaus Failing ${ }^{2}$, Hartwig Bostedt ${ }^{1}$ \\ ${ }^{1}$ Clinic for Obstetrics, Gynecology and Andrology of Large and Small Animals with Ambulatory Service, Faculty of Veterinary Medicine, \\ Justus Liebig University, Giessen, Germany \\ ${ }^{2}$ Unit for Biomathematics and Data Processing, Veterinary Faculty, Justus Liebig University, Giessen, Germany
}

\section{Email address:}

wolfgang.zaremba@veyx.de (W. Zaremba)

${ }^{*}$ Corresponding author

\section{To cite this article:}

Wolfgang Zaremba, Thomas Udluft, Klaus Failing, Hartwig Bostedt. Analysis of the Course of Birth and the Early Postpartal Period in Pigs After Hormonal Partus Induction with Special Consideration of Complication Rate. Animal and Veterinary Sciences.

Vol. 7, No. 2, 2019, pp. 29-39. doi: 10.11648/j.avs.20190702.11

Received: March 12, 2019; Accepted: April 22, 2019; Published: May 11, 2019

\begin{abstract}
The aim of this field study was to analyse the course of parturition in sows, differentiated by eutocia and dystocia, after previous partus synchronisation. The study included 1,975 sows of a closed herd divided into 5 groups: Sows having farrowed until or on day 114 post conception served as controls $(\mathrm{A} ; \mathrm{n}=710)$. Sows in which parturition did not commence until or during day 114 were treated with a $\mathrm{PGF}_{2 \alpha}$-analogue (cloprostenol $175 \mu \mathrm{g} \mathrm{IM}$ ). Sows which started to farrow within 24 hours post injection were assigned to group B $(\mathrm{n}=719)$. Sows which did not start giving birth within 24 hrs post injection were treated with IM injection of either oxytocin (20 I. E.; group C; $n=180)$ or carbetocin in two different dosages $(70 \mu \mathrm{g}$ : group $\mathrm{D}$, $\mathrm{n}=175$; or $35 \mu \mathrm{g}$ : group $\mathrm{E}, \mathrm{n}=191$ ). Sows were monitored continuously during the trial period. According to the results of analysis, time until beginning of the expulsion stage (II) was significantly shortened after partial partus induction in sows with eutocia in groups $\mathrm{C}, \mathrm{D}$, and $\mathrm{E}$ compared to group B $(P \leq 0.001)$. A statistically significant prolongation $(P<0,0001)$ was observed in sows with dystocia. The dystocia rates were: control group (A) $11.5 \%$, group B 19.5\%, group C 18.3\%, group D $11.4 \%$, and group E $13.6 \%$. After partus induction, percentage of stillborn piglets (eutocia) showed an overall significant decrease $(P<0.002-0.05)$ in correlation to reduction of duration of parturition.
\end{abstract}

Keywords: Sows, Partus Synchronization, Eutocia-/Dystocia-Proportion

\section{Introduction}

In piglet production, hormonal induction of partus in sows by single injection of $\mathrm{PGF}_{2 \alpha}$ around day 114 of gestation and also regulation of labour during stage II of parturition (expulsion stage) with oxytocin or carbetocin, respectively, are well established routine biotechnical procedures. Associated benefits are the possibility of planning the date of parturition with the aim of optimising organisation and work flow within the farrowing unit of the farm. At the same time, monitoring of parturition can be intensified, which means shorter duration of parturition and reduction of number of stillborn piglets [1-2]. Only episodic, local data about frequency of use of partus induction by biotechnological methods are available. For example, [3] reported that induction of parturition was applied by $76 \%$, and intrapartal oxytocin by $68 \%$ of their pig farm clients in a district of Canada.

According to [4], interventions in order to assist labour were customary in $76 \%$ of Mexican, family-owned pig farms. [5] reported induction of parturition being a routine procedure in $29.9 \%$, and administration of oxytocin during parturition in $40.2 \%$ of Belgian-Flemish herds with $>150$ sows. Global data concerning use of these biotechnical strategies comparing different countries are, however, not available at present.

In contrast, various effects of total or partial 
synchronisation of parturition in sows have been described extensively [6-10, 1, 11-17, 2]. Published data mainly refer to percentage of stillborn piglets or liveborn piglets, respectively, early postnatal piglet losses, and percentage of weaned piglets and their weight gain. Only few studies investigate the course of parturition as such after partus induction with $\mathrm{PGF}_{2 \alpha}[3,18,5,19,2]$. No comparative analysis of the various methods of synchronisation of parturition differentiating eutocic and dystocic courses of parturitionparturition is available so far.

Therefore, the aim of this study was to investigate parturition in sows by comparing different methods aiming at influencing parturition, and their effects on eutocia, dystocia, and also on the early postpartal period under standardised housing and keeping conditions. Data collected in this study were used to analyse critical aspects of the different biotechnical techniques for partus induction in this livestock species.

\section{Material and Methods}

\subsection{Animals}

The present study was conducted on a closed piglet producing farm with 1,400 sows (rotation cross breed Large White x German Landrace) kept under controlled conditions. Breeding station, waiting house, and farrowing unit were located in separate buildings. A high hygienic standard was secured in all 3 units. An integrated, veterinary controlled health monitoring system with vaccination system and systematic prophylactic parasite control was carried out on the whole farm. Feeding of breeding animals was adapted to reproduction stage. For example, sows received $3.0-3.5 \mathrm{~kg}$ complete feed containing $12.6 \mathrm{MJ} / \mathrm{kg}$ throughout the last trimester of gestation.

\subsection{Preparation of Sows for Parturition}

Sows were washed around day 105 of gestation and checked for their condition with special emphasis on their health status (general health, condition of mammary glands, skin, legs and claws). In case of a normal health check and condition check result, sows were transferred to the farrowing unit, where they were housed in individual pens equipped with a box stand. A movement area was available for the piglets, and also an avoidance area equipped with a heat source.

Late pregnant sows with abnormal findings concerning prepartal condition and health were not included in the study.

Within a period of 9 months, 1,975 parturitions of healthy sows were documented. $59 \%$ of the sows were multiparous, $41 \%$ were primiparous. A total of 1,833 data sets were available for analysis.

\subsection{Techniques for Synchronisation of Parturition and Group Assignment}

Sows which farrowed until or on day 114 of gestation served as controls $(n=710$; group A). Sows that showed no signs of parturition up to or on day 114 of gestation, respectively, received an IM injection of the $\mathrm{PGF}_{2 \alpha}$-agonist cloprostenol $(175 \mu \mathrm{g})$. Treated sows in which parturition started within $24 \mathrm{hrs}$ post injection were assigned to group B $(\mathrm{n}=719)$. Sows treated with cloprostenol showing no detectable signs of parturition were treated either with $20 \mathrm{I}$. U. oxytocin IM (group C; $\mathrm{n}=180$ ), with $70 \mu \mathrm{g}$ carbetocin IM (group $\mathrm{D} ; \mathrm{n}=175$ ), or with $35 \mu \mathrm{g}$ carbetocin IM (group E; $\mathrm{n}$ = 191), respectively. Additional medication in groups C, D, and $\mathrm{E}$ were alternated weekly. Hormone preparations were provided by Veyx Pharma GmbH (Schwarzenborn, Germany).

\subsection{Monitoring of the Peripartal Period}

From day 112 of gestation, a $24 \mathrm{hrs}$ continuous monitoring was performed by qualified farm staff. In addition to general data (number and time of parturition etc.) the course of each parturition was recorded individually by means of a specific protocol. Futhermore, each newborn piglet was examined immediately. Newborn piglets were freed from birth membranes, amniotic fluids, and rubbed dry. The umbilical cord was shortened if necessary, and the umbilicus was disinfected. Underweight piglets and piglets with reduced vitality were assisted with suckling by placing them directly at the sow's teat.

During the early postpartal period (up to day 10 post partum) sows and piglets were also closely monitored and examined daily. Findings were documented in a protocol. Criteria for assessing the sow's health were body temperature, feed intake, consistency of feces, willingness to let piglets suckle, maternal behaviour, condition of mammary glands as well as colour and consistency of vaginal fluor, and also vitality and mobility of the piglets.

\subsection{Definitions and Data Collection}

Apart from the a.m. data recorded during parturition, the following was documented in addition: start of expulsion (stage II of parturition) after medication, duration of birth, interval between birth of individual piglets, dystocia (differentiated by each third of parturition), number of piglets born alive and of stillborn piglets, respectively. Different numbers of animals in tables are due to the fact that some protocols were incomplete. Incomplete data protocolling only concerned single parameters, however.

Parturition was classified as normal (eutocia), when no obstretical intervention, neither manually nor otherwise was necessary, and duration did not exceed a certain time limit. Time limit was set according to intervals of expulsion of piglets. Regular expulsion of piglets was defined as a maximum of 45 minutes between birth of 2 piglets. Sows were grouped in the dystocia group whenever disturbances of parturition (strong, uncoordinated labour without expulsion of a piglet) were apparent, or interruption of parturition (inreasing labour with intervals of expulsion $>45$ minutes) was observed, respectively.

Dystocia was hence defined as a disturbance or 
prolongation of parturition, respectively, caused by mechanical, functional, or possibly organic impairments.

In case of dystocia, obstetrical examination was performed vaginally following a general examination of the sow. If the piglet was already within the birth canal, it was extracted manually. When no labour contractions could be observed, in case of a missing Ferguson reflex, and if position of the piglet was either digitally ante- or intrapelvic, respectively, oxytocin/carbetocin (20 I.U; $70 \mu \mathrm{g}$ or $35 \mu \mathrm{g}$ ) were repeatedly administered.

Indications of disturbances post partum were an increase in body temperature $\left(\geq 39.8^{\circ} \mathrm{C}\right)$ in connection with general inanition. Additional criteria were reduced food intake, increase or lack of water intake, coprostasis or diarrhoe, respectively, mastitis in one or more mammary complexes, insufficient milk production, discoloured, odorous vaginal fluid, vaginal tears, and disturbances of piglet health (piglet starvation syndrome/hypoglycaemia, reduced vitality). In most cases, multiple clinical symptoms were observed, so that at least 2 more symptoms apart from fever and anorexia had to be present for a diagnosis of postpartal syndrome.

Antibiotic, antiinflammatory and substitution therapy was specifically tailored to the individual case concerning use of drugs, substitutes, and duration of treatments.

\subsection{Statistical Evaluation}

Statistical analysis of data was carried out by using the following programmes: BMDP [20], BiAS [21] and R (Free Software Foundation's GNU Project [22]). Different statistical methods were applied depending on study design and scale levels of documented target variables [23].

Normally, data were described by arithmetic means $(\bar{X})$ and standard deviations (s). Variables with right-skewed distributions were logarithmically transformed prior to statistical evaluation in order to obtain a near normal distribution curve. Concerning data were described as geometric means and dispersion factors.

Percentage of sows with eutocia and dystocia, respectively, as well as of postpartum diseases in the various treatment groups (in the overall collective and also in groups with eutocia and dystocia) were analysed using the Chi-Square test followed by pairwise group comparison controlling the global type I error probability using the Bonferroni-Holm method. Additionally, 95\% confidence intervals of the percentages were calculated.
Comparison of means between different treatment groups and different course of parturition (eutocia vs. dystocia) were performed by two-factorial ANOVA (software BMDP7D) sometimes followed by a one-factorial ANOVA for comparison of treatments within the eutocia and the dystocia group, respectively. Addtionally, a pairwise comparison with the untreated group serving as control using a multiple t-test with adjusted $\alpha$-values using the the Bonferroni-Holm method followed. Since duration of parturition was also dependent on number of piglets, a two-factorial ANCOVA with litter size as covariable was performed in addition (program BMD2V).

For the number of stillborn piglets a two-factorial comparison of groups was performed by Poisson regression using a generalised linear mixed model (glmm analysis, software R) including the covariate litter size and the factors medication and course of parturition and their interaction. Again a comparison of groups within the eutocia and the dystocia group followed using an analogue one-factorial method. Data of the variable number of stillborn piglets were described in form of a box-and-whisker plot.

\section{Results}

\subsection{Course of Parturition}

The percentages of eutocia and dystocia, respectively, differed between groups (Table 1). Global statistical comparison of all treatment groups concerning percentage of dystocia showed significant divergences $(P<0.001)$. While percentage of sows with dystocia was $11.5 \%$ in the control group (A), it was $19.5 \%$ in the group of sows treated with $\mathrm{PGF}_{2 \alpha}(\mathrm{B})(P<0.001)$. Sows treated with $\mathrm{PGF}_{2 \alpha}$ plus oxytocin (C) showed a similar percentage of dystocia $(18.3 \% ; P=0.015)$. In contrast, percentage of dystocia was similiar to that of controls (A; Table 1) in groups D and E $(P>0.05)$. Table 1 shows confidence intervals for percentages of dystocia within different groups. Groups B and $\mathrm{C}$ showed a markedly higher rate of dystocia. According to these results, techniques for partus synchronisation using either only $\mathrm{PGF}_{2 \alpha}$ or $\mathrm{PGF}_{2 \alpha}$ in combination with oxytocin $(24$ hrs after the first injection) are inferior to techniques using $\mathrm{PGF}_{2 \alpha}$ in combination with carbetocin as a long-actingoxytocin $(70$ or $35 \mu \mathrm{g})$.

Table 1. Percentage of sows with eutocia and dystocia, respectively, grouped by method of hormonal induction of parturition.

\begin{tabular}{|c|c|c|c|c|c|c|c|}
\hline \multirow{3}{*}{ Group } & \multirow{3}{*}{ Medication } & \multirow{3}{*}{$\mathbf{n}$} & \multicolumn{4}{|c|}{ Course of parturition (\%) } & \multirow{3}{*}{$\begin{array}{l}95 \% \text {-confidence interval } \\
\text { for dystocia (\%) }\end{array}$} \\
\hline & & & \multicolumn{2}{|c|}{ eutocia } & \multicolumn{2}{|c|}{ dystocia } & \\
\hline & & & n & $\%$ & n & $\%$ & \\
\hline $\mathrm{A}$ & none & 710 & 628 & 88.5 & 82 & $11.5^{\mathrm{a}}$ & $9.3-14.1$ \\
\hline B & $\mathrm{PGF}_{2 \alpha}$ & 719 & 579 & 80.5 & 140 & $19.5^{\mathrm{b}}$ & $16.6-22.6$ \\
\hline $\mathrm{C}$ & $\mathrm{PGF}_{2 \alpha}+\mathrm{Oxy}$ & 180 & 147 & 81.7 & 33 & $18.3^{\mathrm{c}}$ & $13.0-24.8$ \\
\hline $\mathrm{D}$ & $\mathrm{PGF}_{2 \alpha}+$ Carb. 70 & 175 & 155 & 88.6 & 20 & $11.4^{\mathrm{d}}$ & $7.1-17.1$ \\
\hline $\mathrm{E}$ & $\mathrm{PGF}_{2 \alpha}+$ Carb. 35 & 191 & 165 & 86.5 & 26 & $13.6^{\mathrm{e}}$ & $9.1-19.3$ \\
\hline
\end{tabular}

A: B $P<0.001 ;$ A: C $P=0.015 ;$ A: D $P>0.05$; A: E $P>0.05$.

Causes for disturbed parturition were almost identical throughout all groups, with hypotonic labour at the beginning 
of the expulsion stage, or successive degression of intensity of labour up to complete inertia (absent Ferguson reflex). Other causes were a relatively too large fetus, and, more rarely, malpresentation. Those obstetrical problems were associated with prolongation of the individual expulsion phase, and thereby with a (secondary) degression of labour.

Two-factorial ANOVA (based on logarithmic transformed values) shows a statistically high difference between treatment groups and also between eutocia and dystocia, respectively, already at the beginning of the expulsion stage (stage II) post medication $(P<0.001$; Table 2, Figure 1). There was, however, no significant interaction between these factors $(P=0.89)$.

In sows with dystocia, time span between medication and start of parturition was longer compared to sows showing a normal course of parturition. This difference was particularly pronounced in sows treated with a single injection of $\mathrm{PGF}_{2 \alpha}$ (Table 2, Figure 1). Geometric mean was 615 minutes in sows with eutocia, and 916 minutes in case of dystocia (global comparison $+48.9 \% ; \quad P<0.001$ ). Pairwise comparison revealed a highly significant difference for duration of the expulsion stage between sows treated with
$\mathrm{PGF}_{2 \alpha}$ and all other treatment groups $(P<0.001)$. No significant difference was found within the other treatment groups (Figure 1).

Table 2. Average start of stage II of parturition (geometric mean $\left(\overline{\mathrm{x}}_{g}\right)$ in minutes as well as dispersion factor (SF) in sows after hormonal induction of parturition depending on type of medication and eutocia or dystocia, respectively. Global comparison by two-factorial ANOVA: between medications: $P<0.001$, eutocia vs. dystocia: $P<0.0001$; interaction: $P=$ 0.89 (n.s.).

\begin{tabular}{lllll}
\hline & \multicolumn{4}{l}{ Start of parturition with subsequent } \\
\cline { 2 - 5 } Group/Medication & eutocia & \multicolumn{3}{c}{ dystocia } \\
\cline { 2 - 5 } & $\mathbf{n}$ & $\overline{\mathrm{x}}_{\mathbf{g}} ; \mathbf{S F}$ & $\mathbf{n}$ & $\overline{\mathrm{x}}_{\mathbf{g}}$ : SF \\
\hline $\mathrm{PGF}_{2 \alpha}$ & 526 & $615^{\mathrm{A}} ; 2.33$ & 131 & $916^{\mathrm{a}} ; 2.03$ \\
$\mathrm{PGF}_{2 \alpha}+$ Oxy & 134 & $76.4^{\mathrm{B}} ; 3.01$ & 30 & $121^{\mathrm{b}} ; 2.06$ \\
$\mathrm{PGF}_{2 \alpha}+$ Carb. 70 & 155 & $67.6^{\mathrm{C}} ; 2.52$ & 17 & $88.5^{\mathrm{c}} ; 2.54$ \\
$\mathrm{PGF}_{2 \alpha}+$ Carb. 35 & 162 & $59.4^{\mathrm{D}} ; 2.40$ & 24 & $96.4^{\mathrm{d}} ; 2.15$ \\
\hline
\end{tabular}

Pairwise comparison of groups with different medication in sows with eutocia and dystocia, respectively:

A: B $P<0.001$ a: b $P<0.001$ A: C $P<0.001$

a: c $P<0.001$ A: D $P<0.001$ a: $\mathrm{d} P<0.001$

B: Cn. s. b: c n. s. B: D $P=0.052$

b: d n. s. C: D n. s. c: d n. s.

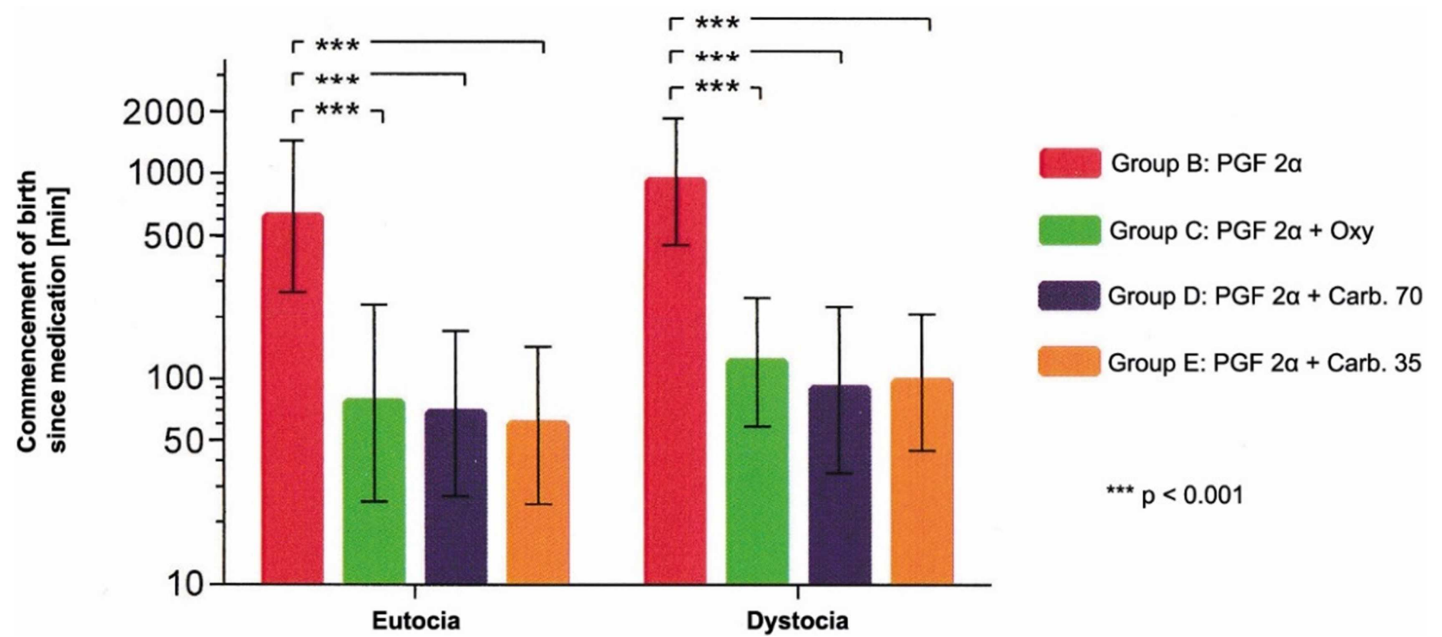

Figure 1. Commencement of birth (stage II) after hormonal partus induction and subsequent eutocic or dystocic course. Data as the geometric mean value and the dispersion factor $\left(\overline{\mathrm{x}}_{\mathrm{g}} ; \mathrm{DF}\right)$; represented using a logarithmic scale.

Relations between methods for synchronisation of parturition and total duration of parturition were also evaluated. Global two-factorial comparison of mean values of groups of sows with dystocia and eutocia without consideration of litter size as a possible influencing factor revealed highly significant differences $(P<0.0001)$. Highly significant differences were also found between groups with different medication protocols $(P<0.0001)$. First-order interaction was marginally significant $(P=0.099)$. For this reason, a one-factorial analysis of treatments differentiated by course of parturition (eutocia resp. dystocia) was carried out. Litter size was not included as an influencing factor. While there were significant differences within the eutocia group $(P<0.001-0.05)$, no differences were found in the dystocia group (Table 3, Figure 2). As mentioned above, a marginally significant difference was found concerning the interaction as an indication of this result. However, the lower number of sows in the dystocia group resulted in a marked reduction of statistical power in this group.

Table 3. Duration of parturition [min] grouped by uncomplicated and complicated course of parturition in groups $A-E$, respectively.

\begin{tabular}{|c|c|c|c|c|c|c|c|}
\hline \multirow[t]{2}{*}{ Group } & \multicolumn{3}{|c|}{$\begin{array}{l}\text { Uncomplicated course } \\
\text { of parturition }\end{array}$} & \multicolumn{3}{|c|}{$\begin{array}{l}\text { Complicated course of } \\
\text { parturition * }\end{array}$} & \multirow[t]{2}{*}{$P$-value } \\
\hline & $\mathrm{n}$ & $\bar{x}$ & \pm SD & $\mathrm{n}$ & $\bar{x}$ & \pm SD & \\
\hline A & 585 & 240 & 84 & 69 & 306 & 98 & $<0.0001$ \\
\hline B & 526 & 230 & 82 & 131 & 307 & 98 & $<0.0001$ \\
\hline $\mathrm{C}$ & 134 & 209 & 68 & 30 & 304 & 116 & $<0.0001$ \\
\hline D & 155 & 186 & 57 & 17 & 310 & 123 & $<0.0001$ \\
\hline E & 162 & 184 & 53 & 24 & 251 & 104 & 0.0002 \\
\hline
\end{tabular}

* Only 271 exact data were available for the sows with dystocia $(n=301)$. 


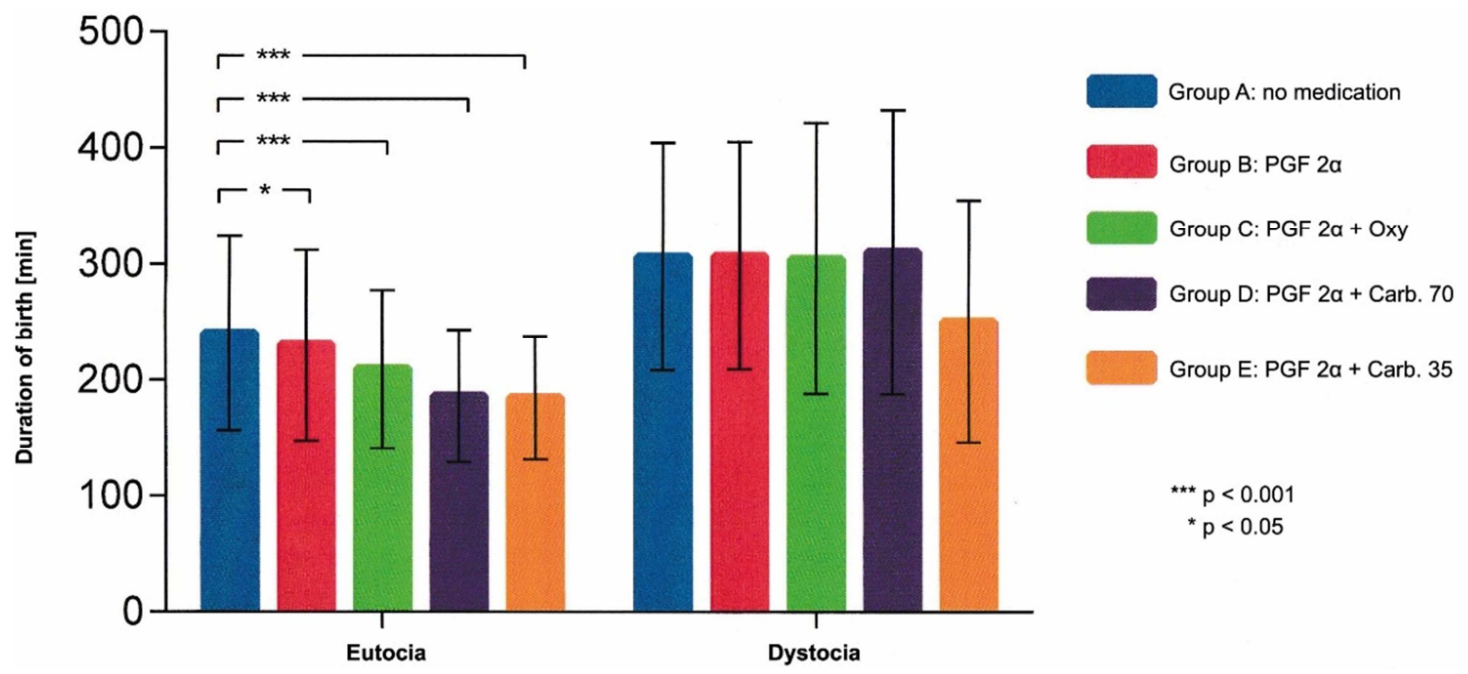

Figure 2. Comparison of the duration of birth between the eutocia and dystocia group $(\overline{\mathrm{x}} \pm S D)$.

Monitoring of parturition also included documentation of time of interruption of labour. In the control group (A), 20.9\% of sows with dystocia showed interruption of labour already during the first third of parturition. Distribution of interruption of labour was, however, almost identical for the second and third part of parturition (Figure 3). In the group of sows treated with $\mathrm{PGF}_{2 \alpha}$-agonists only (group $\mathrm{B}$ ), it was notable that prolongation of duration of parturition occurred already during the 1 st third of parturition, while prolongation could be observed mainly during the 2 nd and 3rd part of parturition in groups $\mathrm{C}, \mathrm{D}$, and $\mathrm{E}$. Fewer disturbances could be observed at the beginnung of stage $\mathrm{II}$ in group $\mathrm{C}\left(\mathrm{PGF}_{2 \alpha}+\right.$ oxytocin), however, dystocia events showed a dramatic increase during the 2nd third of parturition in this group (Figure 3). Data suggest that oxytocin/carbetocin had a positive effect at the beginning of stage II in groups $\mathrm{C}, \mathrm{D}$, and $\mathrm{E}$, however, this effect seemed to decrease in the following stages. In gilts, dystocia seems to have a higher incidence during the last third of parturition, while older sows showed similar dystocia rates during the 2 nd as well as the 3 rd part of parturition.

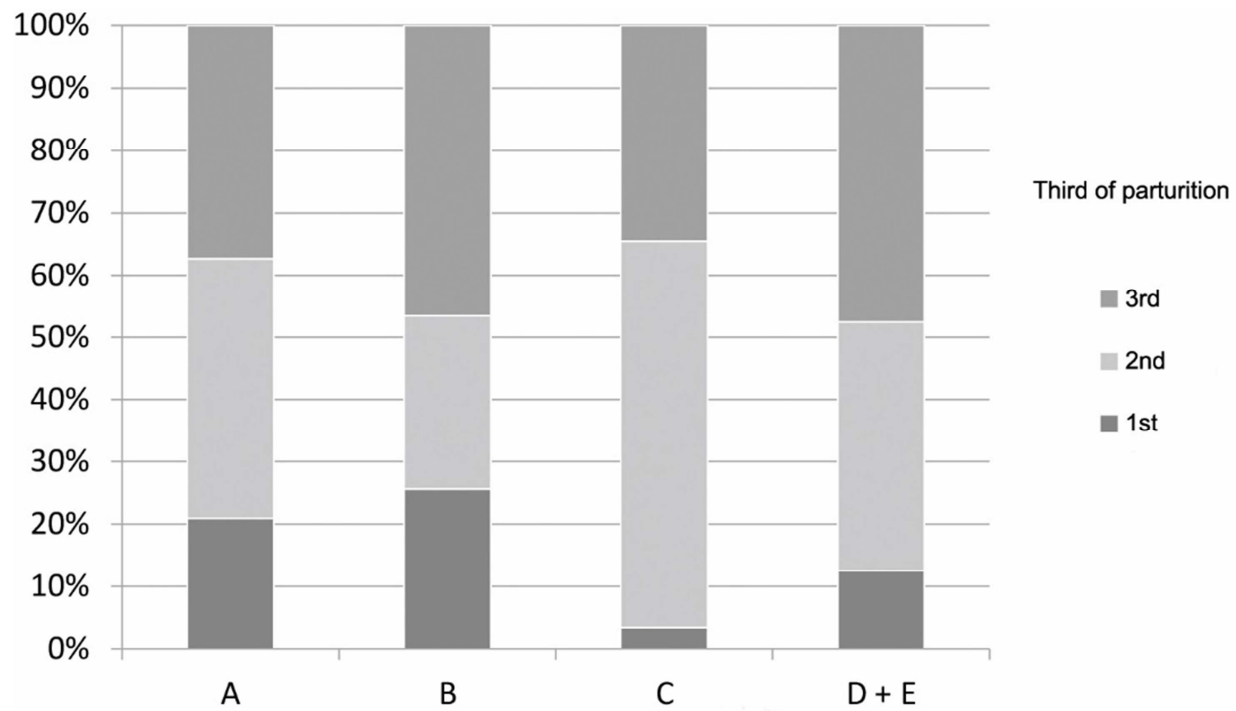

Figure 3. Occurrence of complications during the birth process $\left(1^{\text {st }}, 2^{\text {nd }}\right.$ or $3^{\text {rd }}$ third $)$ in comparison to the different groups.

Since the number of piglets varied between $12.04 \pm 2.96$ and $10.36 \pm 2.83$ in sows with eutocia, one-factorial ANCOVA was used to evaluate relations of duration of parturition and litter size with different techniques of synchronisation of farrowing. Litter size had a highly significant effect on duration of parturition $(P<0.0001)$ with a regression coefficient of $\mathrm{m}=5.26 \mathrm{~min} /$ piglet. Hence, mean prolongation of total expulsion (stage II) is about 5.3 min/additional piglet. Regarding this increase there was no statistical difference between treatment groups $(P=0.83)$.
Adjusted means were calculated by using this regression coefficient (correction of litter size throughout all litters to a number of 11.52 piglets). Differences of adjusted means between the various synchronisation techniques were also highly significant (Table 3; $P<0.0001$ ). Differences to controls that were calculated earlier show a slight decrease, since controls showed the longest duration of parturition and also the largest litter sizes, however, this emphasises statistical significance. The results can be explained by the fact that the variable duration of parturition showed a 
markedly reduced variance, by considering the number of fetusses/litter.

Sows with dystocia also showed differences between the different groups concerning mean number of piglets. However, no statistically significant correlation of duration of parturition with number of piglets $(P=0.92)$ and also treatment regime $(P=0.20)$ was found. These results are in agreement with statistical analysis performed without consideration of litter size.

\subsection{Vitality of Piglets}

Ratio of piglets born alive and stillborn piglets decreased in sows with eutocia depending on method of synchronisation of parturition and hence with shortening of duration of parturition (A: E; 1.1: 0.5; Table 4; Figure 4).

Table 4. Mean number of live- and stillborn piglets in sows with eutocia and dystocia, respectively.

\begin{tabular}{|c|c|c|c|c|c|c|c|c|}
\hline \multirow{4}{*}{ Group } & \multicolumn{4}{|c|}{ Uncomplicated course of parturition/eutocia } & \multicolumn{4}{|c|}{ Complicated course of parturition/dystocia } \\
\hline & \multirow{3}{*}{$\mathbf{n}$} & \multirow{2}{*}{$\begin{array}{l}\text { piglets } \\
\text { total } \\
\end{array}$} & \multicolumn{2}{|c|}{ born } & \multirow{3}{*}{$\mathbf{n}$} & \multirow{2}{*}{$\begin{array}{l}\text { piglets } \\
\text { total } \\
\end{array}$} & \multicolumn{2}{|c|}{ born } \\
\hline & & & live & stillborn & & & live & stillborn \\
\hline & & $\overline{\mathrm{x}}$ & $\overline{\mathrm{x}}$ & $\overline{\mathrm{x}}$ & & $\overline{\mathrm{x}}$ & $\overline{\mathrm{x}}$ & $\overline{\mathrm{x}}$ \\
\hline A & 585 & 12.0 & 10.9 & $1,1^{\mathrm{a}}$ & 69 & 11.1 & 9.6 & 1.5 \\
\hline $\mathrm{B}$ & 526 & 11.7 & 10.9 & $0.8^{\mathrm{b}}$ & 131 & 11.5 & 10.6 & 0.9 \\
\hline $\mathrm{C}$ & 134 & 10.8 & 10.0 & $0.8^{\mathrm{c}}$ & 30 & 10.0 & 9.1 & 0.9 \\
\hline D & 155 & 10.3 & 9.7 & $0.6^{\mathrm{d}}$ & 17 & 9.1 & 7.8 & 1.3 \\
\hline E & 162 & 10.6 & 10.1 & $0.5^{\mathrm{e}}$ & 24 & 8.5 & 7.3 & 1.2 \\
\hline
\end{tabular}

a: b $P<0.001$ a: d $P<0.01$ a: c $P>0.05$ a: e $P<0.001$.

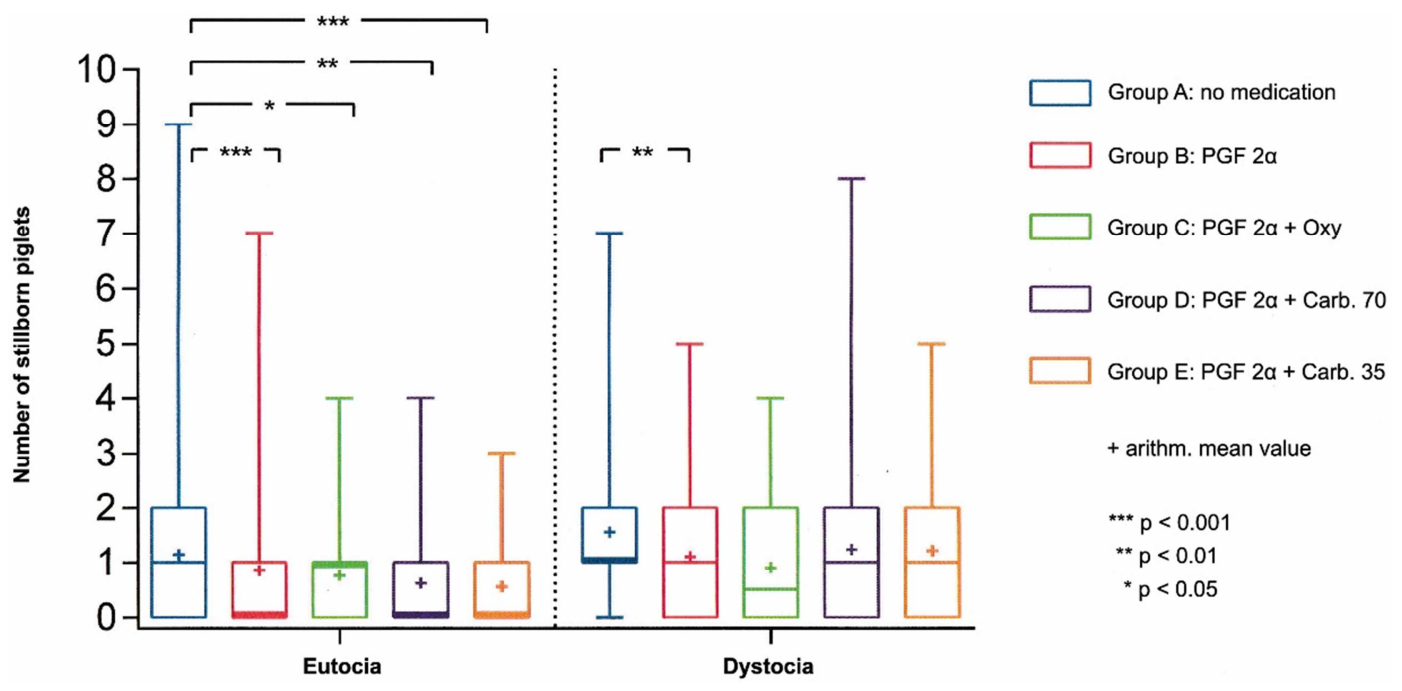

Figure 4. Number of stillborn piglets in the different eutocic and dystocic groups.

Multiple Poisson regression using a generalised linear mixed model was applied for analysis of relations of number of stillborn piglets to eutocia and dystocia, respectively, and to evaluate method of synchronisation of parturition. Expected was an increase of stillborn piglets proportional to the increase of overall mean number of piglets. For this reason, overall number of piglets was included as a covariate in the analysis. The Wald-test was carried out which showed statistically significant differences between groups of sows with different courses of parturition $(P=0.0002)$, and also between treatment groups $(P<0.0001)$. In the dystocia group, adjusted means (effect of litter size included in analysis) were increased by 0.39 piglets. In addition, there was a significant interaction between the two factors treatment and course of parturition $(P=0.0033)$. This shows that differences between treatments are not identical for eutocia and dystocia. Therefore, analysis was repeated separately for eutocia and dystocia, respectively (Table 4; Figure 4). Futhermore, litter size had a statistically highly significant effect on mean number of stillborn piglets $(P<$ $0.0001)$. Regression coefficient was $\mathrm{m}=0.158$ over all groups. This means that, on average, number of stillborn piglets increased by 0.158 for each additional piglet per litter.

In sows with eutocia, number of stillborn piglets showed an even more pronounced dependancy on total number of piglets $(\mathrm{m}=0.170 ; P<0.0001)$. Effects of different treatments were also highly significant $(P<0.0001)$. Differences were validated by pairwise group comparison $(P$ $<0.001-0.05$; Figure 4$)$. The lowest number of piglet losses was recorded in groups D (0.6) and E (0.5), respectively (Table 4).

Mean number of stillborn piglets was increased in sows with dystocia $(P=0.0002)$, variations between groups were markedly smaller, but still statistically significant $(P=0.011)$ (Table 4; Figure 4). Relation to litter size was significant, however slightly lower than in sows with eutocia $(\mathrm{m}=0.117$; $P<0.01)$. 


\subsection{Post Partum Period}

Data analysis showed a higher incidence of complications during the postpartum period in the control group (12.82\%) compared to treatment groups $(10.43-7.85 \%$; Table 5$)$. These findings were independent from eutocia or dystocia, respectively. Groups D and E (carbetocin $70 \mu \mathrm{g} / 35 \mu \mathrm{g}$ ) showed comparatively low incidences (8.6 and 7.6\%, respectively). These differences were, however, not significant (group D: $P=0.053$; group $\mathrm{E}: P=0.064$ ). In comparison to group A, significance threshold of $P \leq 0.05$ was only just missed $(P=0.053 ; P=0.064)$. Percentage of disturbances postpartum was higher in sows with dystocia throughout all groups; differences were, however, not significant (Table 6). Sows with spontaneous parturition (A), however, showed the highest percentage $(17.1 \%)$. In contrast, sows with dystocia which had been treated with a $\mathrm{PGF}_{2 \alpha^{-}}$ agonist showed a lower incidence of postpartum disturbances. Comparison of couples for incidence of postpartum disturbances in sows with dystocia did not show any differences, however $(P>0.05)$.

Table 5. Percentage of postpartal disease throughout all groups of sows, independent of course of parturition.

\begin{tabular}{llll}
\hline Group & $\mathbf{n}$ & Number of sows with dystocia & \% \\
\hline A & 710 & 91 & 12.82 \\
B & 719 & 75 & 10.43 \\
C & 180 & 17 & 9.44 \\
D & 175 & 15 & 8.57 \\
& 191 & 15 & 7.85 \\
total & 1975 & 213 & 10.78 \\
\hline
\end{tabular}

Table 6. Comparison of percentage of postpartal disease in groups $A-D+E$, differentiated by course of parturition ${ }^{x x}$.

\begin{tabular}{|c|c|c|c|c|c|c|c|}
\hline \multirow{3}{*}{ Group } & \multirow{3}{*}{$\begin{array}{l}\text { Eutocia } \\
\mathrm{n}\end{array}$} & \multicolumn{5}{|c|}{ Dystocia } & \multirow{3}{*}{$\begin{array}{l}\text { Significance } \\
\text { (P-value) }\end{array}$} \\
\hline & & \multicolumn{2}{|c|}{ Post partum complications } & \multirow{2}{*}{$\mathbf{n}$} & \multicolumn{2}{|c|}{ Post partum complications } & \\
\hline & & $\mathbf{n}$ & $\%$ & & $\mathbf{n}$ & $\%$ & \\
\hline A & 585 & 74 & 12.7 & 82 & 14 & 17.1 & 0.27 \\
\hline B & 526 & 55 & 10.5 & 140 & 18 & 12.9 & 0.42 \\
\hline $\mathrm{C}$ & 134 & 11 & 8.2 & 33 & 5 & 15.2 & 0.22 \\
\hline$D+E^{*}$ & 317 & 23 & 7.2 & 46 & 7 & 15.2 & 0.067 \\
\hline
\end{tabular}

* Numbers of groups D + E were added because of the small group sizes.

Differing numbers of sows compared to table 5 are due to the fact that postpartal protocol was incomplete in some cases.

\section{Discussion}

As in all mammals, the peripartal period must be regarded as a particularly critical time of the reproduction cycle also in the sow. Within this relatively short period, increased physical stress originating from the last third of gestation due to enforced fetal growth add to extreme metabolic, endocrine and psychological stress, which occurs within a time span of only 24 hours, and which reaches its climax intra partum [8, $24,25,15]$. This stress is potentiated by initiation of lactation which starts directly post partum and also by behavioural changes (maternal behaviour).

Additionally, husbandry and also biotechnical measures which are stressful for pregnant sows are carried out on farms during the multidimensionally instable phase shortly before farrowing. Between day 108 and 110 of parturition, sows are rehoused from group housing or tethering, respectively, to a separate farrowing stable. In most cases, this means a box stable with reduced mobility and hence limitations of specific peripartal behaviour. [25] report on the effects of chronic stress during the porcine pre- and intrapartal period on oxytocin and vasopressin describing an imbalance of these two hormones. The authors estimate that parturition is induced hormonally around day $113-115$ of pregnancy in $40 \%$ of the breeding sows. Induction and hence synchronisation of parturition, respectively, by adminstration of $\mathrm{PGF}_{2 \alpha^{-}}$ analogues is performed as a standard procedure and hence without consideration of individual prepartal status of the sow, i.e. of endocrine and metabolic changes directly before parturition, and also behavioural changes. Administration of $\mathrm{PGF}_{2 \alpha}$ results in an abrupt decrease of peripheral progesterone levels, however, it can be doubted whether this decrease matches other equally important maternal and fetal prepartum changes [26-27]. Such hormonal imbalances would have an effect on stage I (opening phase), and also on stage II (expulsion phase) of parturition.

The results of this study show that, after induction of parturition with $\mathrm{PGF}_{2 \alpha}$ at the end of day 114 of gestation, only $56.8 \%$ of the total of 1,265 sows treated entered stage II of parturition (expulsion phase) within 24 hours. In the remaining sows, additional adminstration of other drugs (oxytocin or carbetocin, respectively) 24 hours after injection of the $\mathrm{PGF}_{2 \alpha}$-analogue was necessary for synchronisation of stage II of parturition. This supports doubts already expressed by other authors [26-27] (Table 1.).

In addition, course of parturition itself should be analysed in this context. In sows without hormonal synchronisation of parturition on day $113 / 114$ of gestation, eutocia/ dystocia ratio was 88.5 : 11.5. Percentage of dystocia must, however, be interpreted considering several factors, e.g. farrowing in a box stand, 24-hour-monitoring of sows directly prior to and during farrowing, precise documentation of course of parturition, indications for obstretical interventions whenever interval between expulsion of piglets was greater than $45 \mathrm{~min}$ due to suspended labour or frustane expulsive labour (fetus relatively too large; [28]).

Only few studies are available that allow comparison of the eutocia/dystocia ratio concerning spontaneous parturition as recorded in this study due to differences of husbandry 
conditions. A lower percentage $(5 \%)$ of dystocia in sows with spontaneous parturition was reported by [29]. [18] reported a similar percentage $(7.5 \%)$. Results of [30], however, are similar to those of our own study $(14.2 \%)$. Other studies quoting dystocia rates for spontaneous parturition in sows are not comparable due to several reasons. On the one hand, data were not documented during parturition itself according to criteria defined beforehand, but data were collected retrospectively from several farms with different management methods of parturition by means of a questionnaire $[11,5]$. On the other hand, dystocia rates were related to the number of manually developed piglets, or duration of parturition was selected as a criterium for dystocia [31, 14, 32].

According to the results of this study, dystocia rates may vary from rates reported for spontaneous parturition when parturition is artificially induced. Dystocia rate significantly increased to $19.5 \%(P<0.001)$ after administration of the $\mathrm{PGF}_{2 \alpha}$-agonist cloprostenol. Coefficient interval was 16.6$22.6 \%$ (Table 1). [33] reported an even higher dystocia rate (28\%) for sows which were kept under comparable conditions and which underwent induction of parturition with cloprostenol. Dystocia rate dropped only insignificantly $(18.3 \%)$ after additional administration of oxytocin in sows which had not reached stage II after 24 hours. Dystocia rates decreased $(11.4 ; 13.6 \%)$ and were then comparable to that of controls $(11.5 ; P>0.05)$ only when $70 \mu \mathrm{g}$ or $35 \mu \mathrm{g}$ carbetocin were administered (Table 1).

If different time points of start of parturition are added to these data, it becomes clear that parturition was markedly delayed in those sows treated with $\mathrm{PGF}_{2 \alpha}$ which also showed dystocia later on (10.3: $15.3 \mathrm{hrs} ;+48 \%$; $+9 \%$; Table 2$)$. The same can be observed in group $\mathrm{C}\left(\mathrm{PGF}_{2 \alpha}+\right.$ oxytocin) (1.3: 2.0 hrs). Adminstration of carbetocin (group D, E) resulted in delayed start of parturition, when dystocia occured in the following $(+3.1 \%)$. The in part significantly delayed start of parturition in sows with dystocia suggests that more or less pronounced differences in partus-inductive hormonal and/or metabolic profiles develop after adminstration of a prostaglandin-analogue. [34] described a marked endogenous hormonal reaction after administration of a $\mathrm{PGF}_{2 \alpha}$-analogue on day 112 of gestation. However, measurements in this study only relate to a control interval of 80 minutes post injection of $\mathrm{PGF}_{2 \alpha}$, i.e. not directly to partus induction on days 114-116 post conception. Therefore, the hormonal profile during stage I and II of parturition in sows in which partus is induced on day $113 / 114$ post conception by adminstration of $\mathrm{PGF}_{2 \alpha}$ still remains unknown.

As mentioned above, a $\mathrm{PGF}_{2 \alpha}$ analogue is generally administered routinely without consideration of the actual hormonal profile ante partum, number of piglets and also without knowledge of corpora lutea and weight of the sow. Administration of $\mathrm{PGF}_{2 \alpha}$ might hence not result in a total blockage of progesterone in all sows, but in a partial drop of peripheral progesterone levels in the individual animal.

This could be one reason for disturbances prior to the expulsion phase (i.e. during the preceding stage I) such as protracted relaxation of cervical and vaginal tissues. During the opening phase of parturition, gradual increase of myometrial forces due to labour during transit from stage I to stage II is important besides structural changes of soft tissues of the birth canal, since they push the first piglet caudally through the uteral corpus towards cervix, vagina, and vestibulum. These myometrial forces widen the birth canal temporalily and to its maximum for the next piglets to be born. In this context, it is important to consider that the network of myometrial oxytocin receptors might lack sufficient density due to partial blockage of progesterone, so that oxytocin secreted by the posterior pituitary cannot take sufficient effect [35]. Possibly, elevated progesterone levels might also inhibit a sufficient influx of extracellular $\mathrm{Ca}^{++}$into the myometrial cell with incomplete actin-myosin-complex formation. The described processes could explain why dystocia rate does not decrease in spite of administration of oxytocin $24 \mathrm{~h}$ post injection of $\mathrm{PGF}_{2 \alpha}$ (group C; Table 2). Dystocia rate could only be reduced toward the rate documented in controls by administration of carbetocin, i.e. of long-acting-oxytocin (Table 1). It must be noted, however, that the half-life of oxytocin is 3.4 minutes only [36]. In contrast, carbetocin (1-deamino-1-carba-2-tyrosine (omethyl-oxytocin)), a long-acting-oxytocin, has a half-life of $85 \mathrm{~min}$ [37-38]. The longer half-life of carbetocin could explain why dystocia rate due to weak labour is markedly reduced to a rate similar to that of the control group after adminstration of carbetocin in case of of biotechnical partus induction.

In this context, it is of particular interest at what time disturbances of partus which was an indication for obstretical intervention occurred. In the control group, dystocia was observed during the 1 st third of parturition in $20.9 \%$ of the sows (i.e. approx. every 5 th sow). In sows with partus induction with $\mathrm{PGF}_{2 \alpha}$ only, dystocia was observed in approximately every 4 th sow $(25.2 \%)$. This could again be an indication for insufficient labour during transit from stage I to stage II of parturition in some of the sows, independent from whether partus had been inducted or not. Effects of oxytocin or carbetocin, respectively, administered $24 \mathrm{hrs}$ post injection of the $\mathrm{PGF}_{2 \alpha}$-analogue in case of suspended labour, are described in the following. In groups C-D (Figure 3) obstetrical intervention during the 1 st third of parturition was only necessary in $4 \%$ and $12 \%$ of the sows, respectively. Since the effect of oxytocin is relatively short, obstetrical interventions showed a disporportional cumulation in the 2nd third of parturition (Figure 3).

Group-related total number of piglets showed variations due to random weekly assignment of sows to different methods of partus induction. This was statistically considered when evaluating duration of parturition in sows with eutocia. Litter size was a highly significant determinant for duration of parturition in all sows $(P<0.0001$; regression coefficient $\mathrm{m}=5.26 \mathrm{~min} /$ piglet $).$ This confirms general observations, and also data in literature. In spite of this calculation, the result remains evident, since a significant reduction of duration of parturition $(P<0.001)$ can be achieved which 
differs according to the method used. However, this is only true for sows with eutocia. This indicates that sows with eutocia show a regular partus-associated homone profile, particulary a profile which determines labour, and that they are metabolically balanced.

In sows with eutocia, duration of parturition was shortened depending on method of artificial partus inducation, and this was also related with an increase in number of live born piglets. There was a significant reduction of the stillborn rate from 1.1 to 0.5 in group A-E $(P<0.002-0.05)$ (Table 4; Figure 4). In comparison to the results of this study, [29] reported a higher stillborn rate (1.6 vs. 1.1 in the present study) for sows with spontaneous parturition. [39] found a variable stillborn rate in 5 different pig breeds (0.2-0.9/litter). It must be noted that adminstration of oxytocin or carbetocin in the early stage II of parturition had no negative effect on the stillborn rate. This is in contrast to observations made by $[4,30,40]$. Both studies report a decrease in fetal heart rate, rupture of the umbilical cord, and intrauterine passing of meconium, all signs of intrauterine hypoxia, after administration of oxytocin (1 IU/6 kg body weight of the sow) following expulsion of the first piglet, which resulted in an overall increase in stillborn rate. According to [4, 30, 41], this effect is due to an oxytocin-induced increased uterine contractability and hence to intervals of hypoxemia. However due to the short half time of oxytocin [36], the effect should have been limited to a short period of time. Myometrical spasms may, however, have developed in case of frequent adminstration of oxytocin at short intervals. [42] reported that sub partu administration of oxytocin or carbetocin, respectively, does not result in a decrease of fetal intravasal $\mathrm{pH}$, and that there were no differences compared to spontaneously born piglets. In consequence, postnatal $\mathrm{pH}$ as measured 2 hours post natum was physiologically higher in both groups $(\mathrm{pH}=7.4000-7.4500)$.

In our study, we also evalutated frequency of the postpartal syndrom, also described as postpartal dysgalactia syndrome [43], puerperal septicaemia-toxaemia syndrome [44], or as MMA-complex [45], respectively (Table 5, 6). There was a marked decrease in correlation to biotechnical techniques of partus induction. However, this decrease was statistically insignificant. Percentage was 10.8 throughout all groups. In contrast to general opinion that the postpartal syndrom occurs more frequently in sows with protracted parturition, particularly when manual obstetrical intervention was necessary, this could not be proven statistically (Table 6). Compared to sows with eutocia, incidence was higher in sows with dystocia (14.6\% vs. $10.4 \%$ ), the differences were, however, not significant for neither global comparison nor comparison between groups. In sows with spontaneous parturition, independent from the fact whether partus was undisturbed or disturbed, percentage of sows with elevated body temperature was higher, however (eutocia $12.7 \%$, dystocia $17.1 \%$ ), than in the treatment groups (eutocia 9.2\%, dystocia 13.7\%). This might be due to a shorter duration of parturition after hormonal partus induction. Similar observations were made by [6]. In our study, incidence of elevated body temperature was $22.9 \%$ in the control group, and $10 \%$ on average in sows in which partus had been induced by alfaprostol. A former study by [46] on postpartal disturbances in sows with spontaneous parturition also reported a higher incidence (gilts 20.5\%, older sows 19.1\%) compared to results of the present study. Comparison of the results of older studies on postpartal disturbances and newer data shows remarkable differences, because it is obvious that percentages show a marked decrease. This could be due to improved hygiene conditions in pig breeding.

\section{Conclusion}

This study presents some interesting facts concerning the course of parturition and the early postpartum period in sows with or without partus induction, particularly in view of duration of parturition, percentages of sows with dystocia, number of vital and stillborn piglets, respectively, and incidence of postpartal disturbances. Dystocia rates showed a various overall increase, with differences, however, depending on method of artificial partus induction. Duration of parturition, number of stillborn piglets and incidence of postpartal disturbances were all positively influenced depending on the partus induction method. However, as a general statement, this is only true for sows with eutocia.

\section{Conflict of Interest}

The authors declare that they have no competing interests.

\section{References}

[1] Zaremba W., Hühn U., 1999. The influence of biotechnical birth control on the characteristics of the litter quality in adult sows. Züchtungskde. 71, 371-379.

[2] Zaremba W., Udluft T., Bostedt H., 2015. Effects of various procedures for synchronisation of parturition in sows. Assessment of sows with a complication-free birth. Tierärztl. Prax. 43 (G), 269-277.

[3] Ravel A., D'Allaire S., Bigras-Poulin M., 1996. Survey of management and housing in farrowing quarters among independent and integrated swine farms in Québec. Can. J. Vet. Res. 60, 21-28.

[4] Mota-Rojas D., Martínez-Burnes J., Trujillo-Ortega M. E., Alonso-Spilsbury M., Ramírez-Necoechea R., López A., 2002. Effect of oxytocin treatment in sows on umbilical cord morphology, meconium staining, and neonatal mortality of piglets. Am. J. Vet. Res. 63, 1571-1574.

[5] Vanderhaeghe C., Dewulf J., Ribbens S., de Kruif A., Maes D., 2010. A cross-sectional study to collect risk factors associated with stillbirths in pig herds. Anim. Reprod. Sci. 118, 62-68.

[6] Holtz W., Hartmann F. J., Welp C., 1983. Induction of parturition in swine with prostaglandin analogs and oxytocin. Theriogenology 19, 583-592. 
[7] Dial G., Almond G., Hilley H. D., Repasky R. R., Hagen J., 1987. Oxytocin precipitation of prostaglandin-induced farrowing in swine: determination of the optimal dose of oxytocin and optimal interval between prostaglandin $\mathrm{F}_{2 \alpha}$ and oxytocin. Am. J. Vet. Res. 48, 966-970.

[8] Guthrie H. D., Meckley P. E., Young E. P., Hartsock T. G., 1987. Effect of altrenogest and Lutalyse on parturition control, plasma progesterone, unconjugated estrogen and 13,14dihydro-15-keto-prostaglandin $\mathrm{F}_{2 \alpha}$ in sows. J. Anim. Sci. 65, 203-211.

[9] Friendship R. M, Templeton C. L., Deckert A. E., 1990. An evaluation of vulvomucosal injections of prostaglandins for induction of parturition in swine. Can. Vet. J. 31, 433-436. Friendship R. M, Templeton C. L., Deckert A. E., 1990. An evaluation of vulvomucosal injections of prostaglandins for induction of parturition in swine. Can. Vet. J. 31, 433-436.

[10] Hühn U., 1992. Ergebnisse mehrjähriger Verfolgungsuntersuchungen zur Geburtssynchronisation in Sauenherden. Mh. Vet. Med. 47, 317-323.

[11] Borges V. F., Bernardi M. L., Bortolozzo F. P., Wentz I., 2005 Risk factors for stillbirth and foetal mummification in four Brazilian swine herds. Prev. Vet. Med. 70, 165-176.

[12] Canario L., Roy N., Gruand J., Bidanel J. P., 2006. Genetic variation of farrowing kinetics traits and their relationships with litter size and perinatal mortality in French Large White sows. J. Anim. Sci. 84, 1053-1058.

[13] Kaeoket K., 2006. The effect of dose and route at administration of R-cloprostenol on the parturient response of sows. Reprod. Domest. Anim. 41, 472-476.

[14] Mesa H., Safranski T. J., Cammack K. M., Weaber R. L., Lamberson W. R., 2006. Genetic and phenotypic relationships of farrowing and weaning survival to birth and placental weights in pigs. J. Anim. Sci. 84, 32-40.

[15] Vallet J. L., Miles J. R., Brown-Brandl T. M., Nienaber J. A., 2010. Proportion of the litter farrowed, litter size, and progesterone and estradiol effects on piglet birth intervals and stillbirths. Anim. Reprod. Sci. 119, 68-75.

[16] Nguyen K., Cassar G., Friendship R. M., Dewey C., Farzan A., Kirkwood R. N., 2011. Stillbirth and preweaning mortality in litters of sows induced to farrow with supervision compared to litters of naturally farrowing sows with minimal supervision. J. Swine Health Prod. 19, 214-217.

[17] Nguyen K., Cassar G., Friendship R. M., Dewey C., Farzan A., Kirkwood R. N. et al., 2013. An investigation of the impacts of induced parturition, birth weight, birth order, litter size, and sow parity on piglet serum concentations of immunoglobulin G. J. Swine Health Prod. 21, 139-143.

[18] Heide J., 1997. Untersuchungen zur Uterusmotorik der puerperalen Zuchtsau und zur Wirkung verschiedener Uterotonika. Ph.D. dissertation, University of Veterinary Medicine Hanover, Foundation.

[19] Panzardi A., Bernardi M. L., Mellagi A. P., Bierhals T., Bortolozzo F. P., Wentz I., 2013. Newborn piglet traits associated with survival and growth performance until weaning. Prev. Vet. Med. 110, 206-213.

[20] Dixon W. J., 1993. BMDP Statistical Software Manual, Volume 1 and 2. University of Califonia Press, Berkeley, Los Angeles, London.
[21] Ackermann H., 2010. BiAS. für Windows: Biometrische Analyse von Stichproben, Version 9.08. Epsilon, Hochheim, Darmstadt.

[22] R Foundation for Statistical Computing. R: A Language and Environment for Statistical Computing, version 3.5.1. http://www.r-project.org.

[23] Sachs L., 2003. Angewandte Statistik. $11^{\text {th }}$ edition. Springer, Heidelberg.

[24] Lichtblau K., Bostedt H., Sobiraj A., 1990. Plasmaenzymaktivitäten und Säure-Basen-Haushalt bei Sauen in Abhängigkeit vom Geburtsverlauf (Enzymatic activities and base-acid-balance in the plasma in sows during the peripartal period). Berl. Münch. Tierärztl. Wschr. 103, 182-188.

[25] Lawrence A. B., Petherick J. C., McLean K. A., Deans L., Chirnside J., Vaughan A. et al., 1995. The effects of chronic environmental stress on parturition and on oxytocin and vasopressin secretion in the pig. Anim. Reprod. Sci. 38, 251-264.

[26] Gustafsson B., Einarsson S., Larsson K., Edquist L. E., 1976. Sequential changes of estrogens and progesterone at prostaglandin-induced parturition in the sow. Am. J. Vet. Res. 37, 1017-1020.

[27] Silver M., Comline R. S., Fowden A. L., 1983. Fetal and maternal endocrine changes during the induction of parturition with the PGF analogue, cloprostenol, in chronically catheterized sows and fetuses. J. Dev. Physiol. 5, 307-321.

[28] Hospes R., Bostedt H., Sobiraj A., 1993. Analyse der geburtshilflichen Situation beim Schwein aus klinischer Sicht (Analysis of the obstetrical situation in sows from the clinical point of view). Tierärztl. Prax. 21 (G), 209-216.

[29] Van Rens B. T., van der Lende T., 2004. Parturition in gilts: duration of farrowing, birth intervals and placenta expulsion in relation to maternal, piglets and placental traits. Theriogenology 62, 331-352.

[30] Alonso-Spilsbury M., Mota-Rojas D., Martínez-Burnes J., Arch E., López Mayagoitia A., Ramirez-Necoechea R., et al., 2004. Use of oxytocin in penned sows and its effect on fetal intra-partum asphyxia. Anim. Reprod. Sci. 84, 157-163.

[31] Madec F., Leon E., 1992. Farrowing disorders in the sow: a field study. J. Vet. Med. A. 39, 433-444.

[32] Mainau E., Ruiz-de-la-Torre J. L., Dalmau A., Salleras J. M., Manteca X., 2012. Effects of meloxicam $\left(\right.$ Metacam $\left.^{\circledR}\right)$ on postfarrowing sow behaviour and piglet performance. Animal 6, 494-501.

[33] Geishauser T., Wegner K., Keller A., 2012. Untersuchungen zur Wirkung eines oralen Calcium-Stoßes vor dem Abferkeln auf die Häufigkeit von Geburtshilfe bei Sauen. Züchtungskde. 84, 330-339.

[34] Widowski T. M., Curtis S. E., Dziuk P. J., Wagner W. C., Scherwood O. D., 1990. Behavioral and endocrine responses of sows to prostaglandin in $\mathrm{F}_{2 \alpha}$ and cloprostenol. Biol. Reprod. 43, 290-297.

[35] Blanks A. M., Thornton S., 2003. The role of oxytocin in parturition. BJOG 110 Suppl 20, 46-51.

[36] Gazis D., 1978. Plasma half-lives of vasopressin and oxytocin analogs after iv injection in rats. Proc. Soc. Exp. Biol. Med. 158, 663-665. 
[37] Cort N., Einarsson S., Schams D., Vilhardt H., 1981. Blood concentrations of oxytocin equivalents after single injections of deamino-1-monocarba- [2-O-methyl-tyrosine]-oxytocin in lactating sows. Am. J. Vet. Res. 42, 1804-1806.

[38] Atke A., Vilhardt H., 1987. Uterotonic activity and myometrial receptor affinity of 1-deamino-1-carba-2-tyrosine (O-methyl)-oxytocin. Acta Endocrinol (Copenh) 115, 155-160.

[39] Van Dijk A. J., van Rens B. T., van der Lende T., Taverne M. A., 2005. Factors affecting duration of the expulsive stage of parturition and piglet birth intervals in sows with uncomplicated, spontaneous farrowings. Theriogenology 64 , 1573-1590.

[40] Mota-Rojas D., Martínez-Burnes J., Trujillo M. E., López A., Rosales A. M., Ramírez R. et al., 2005a. Uterine and fetal asphyxia monitoring in parturient sows treated with oxytocin. Anim. Reprod. Sci. 86, 131-141.

[41] Mota-Rojas D., Rosales A. M., Trujillo M. E., Orozeco H., Ramirez R., Alsonso-Spilsbury M., 2005b. The effects of vetrabutin chlorhydrate and oxytocin on stillbirth rate and asphyxia in swine. Theriogenology 64, 1889-1897.
[42] Wehrend A., Stratmann N., Failing K., Bostedt H., 2005. Influence of partus induction on the $\mathrm{pH}$ value in the blood of newborn piglets. J. Vet. Med. A.52, 472-473.

[43] Reiner G., Hertrampf B., Richard H. R., 2009. Postpartales Dysgalaktiesyndrom der Sau - eine Übersicht mit besonderer Berücksichtigung der Pathogenese. Tierärztl. Prax. 37 (G), 305-318.

[44] Bostedt H., Maier G., Herfen K., Hospes R., 1998. Klinische Erhebungen bei Sauen mit puerperaler Septikämie und Toxämie (Clinical examinations in gilts with puerperal septicaemia and toxaemia). Tierärztl. Prax. 26 (G), 332-338.

[45] Ringarp N., 1960. Clinical and experimental investigations into a post-parturient syndrome with agalactia in sows. Acta Agric. Scand. Suppl. 7, 1-166.

[46] Bostedt H., Rudloff P. R., 1983. Prophylactic administration of the beta-blocker Carazolol to influence the duration of parturition in sows. Theriogenology 20, 191-196. 